\title{
КАЧЕСТВО ЖИЗНИ ПАЦИЕНТОВ С ХРОНИЧЕСКИМ ГЕНЕРАЛИЗОВАННЫМ ПАРОДОНТИТОМ ПРИ КУРСОВОМ ПРИМЕНЕНИИ ОЗОНА В СОЧЕТАНИИ С ТРАНСКРАНИАЛЬНОЙ МАГНИТОТЕРАПИЕЙ
}

\author{
(С) Нагорнев С.Н. ${ }^{1}$, Рябцун О.И. ${ }^{2}$, Фролков В.К. ${ }^{3}$, Будняк М.А. ${ }^{4}$, Гуревич К.Г. ${ }^{4}$, Пузырева Г.А. ${ }^{3}$ \\ ${ }^{1}$ Лаборатория изучения проблем изменения климата, биометеорологии и Арктической \\ медицины Центра стратегического планирования и управления медико-биологическими рисками \\ здоровью, Москва; ${ }^{2}$ Стоматология «Ильдент», Москва; ${ }^{3}$ отдел биомедицинских исследований \\ Национального медицинского исследовательского центра реабилитации и курортологии, Москва; \\ ${ }^{4}$ кафедра ЮНЕСКО «Здоровый образ жизни - залог успешного развития» Московского \\ государственного медико-стоматологического университета им. А.И. Евдокимова, Москва \\ E-mail: kgurevich@mail.ru
}

В статье проведен анализ влияния хронического генерализованного пародонтита и способов его лечения на качество жизни пациентов, оцениваемого с помощью валидизированного в России стоматологического опросника ОНІР14 (Oral Health Impact Profile). Показано, что исходное состояние больных хроническим генерализованным пародонтитом характеризовалось выраженным снижением качества жизни и его критериев по сравнению с показателями здоровых лиц. Установлено, что курсовое применение озона в сочетании с транскраниальной магнитотерапией у больных хроническим генерализованным пародонтитом по сравнению с традиционным лечением является более эффективным терапевтическим методом, обеспечивающим достоверную положительную динамику субъективных признаков и основных стоматологических индексов. Совокупность выявленных положительных зависимостей между показателями стоматологического статуса и доменами качества жизни доказывает информативность использования опросника «ОНІР-14» в качестве критерия выбора метода терапии и оценки клинической эффективности проводимого лечения хронического генерализованного пародонтита.

Ключевые слова: качество жизни, стоматологический опросник ОНІР-14, хронический генерализованный пародонтит, озонотерапия, транскраниальная магнитотерапия, стоматологические индексы.

\section{LIFE QUALITY OF PATIENTS WITH CHRONIC GENERALIZED PARODONTITIS}

IN COURSE APPLICATION OF OZONE IN COMBINATION WITH TRANSCRANIAL MAGNETOTHERAPY Nagornev S.N. ${ }^{1}$, Ryabtsun O.I. ${ }^{2}$, Frolkov V.K. ${ }^{3}$, Budnyak M.A. ${ }^{4}$, Gurevich K. G. ${ }^{4}$, Puzyreva G.A. ${ }^{3}$

${ }^{1}$ Laboratory for the Study of Climate Change, Biometeorology and Arctic Medicine of Center for Strategic

Planning and Management of Medical and Biological Health Risks, Moscow; ${ }^{2}$ Dentistry clinics "Ildent", Moscow;

${ }^{3}$ Department of Biomedical Research of National Research Center of Medical Rehabilitation and Balneology, Moscow;

${ }^{4}$ UNESCO department "Healthy lifestyle - the key to successful development»"

of A.I. Evdokimov Moscow State University of Medicine and Dentistry, Moscow

The article analyzes the effect of chronic generalized periodontitis and the methods of its treatment on the life quality of patients which has been assessed by using the Oral Health Impact Profile (OHIP-14) as an oral health questionnaire validated in Russia. It was shown that the initial state of patients with chronic generalized parodontitis was characterized by a marked decrease in the life quality and its criteria in comparison with the indices of healthy individuals. It has been established that the course application of ozone in combination with transcranial magnetotherapy in patients with chronic generalized periodontitis in comparison with traditional treatment is a more effective therapeutic method that provides reliable positive dynamics of subjective signs and basic dental indices. The combination of the revealed positive dependences between the indicators of the dental status and the domains of the life quality proves the informative use of the "OHIP-14" questionnaire as a criterion for choosing the method of therapy and evaluating the clinical effectiveness of the ongoing treatment of chronic generalized periodontitis.

Keywords: quality of life, OHIP-14 dental questionnaire, chronic generalized periodontitis, ozonotherapy, transcranial magnetotherapy, dental indices.

Парадигме современного здравоохранения соответствует представление об улучшении качества жизни (КЖ) человека. Понимая под КЖ интегральную характеристику физического, психологического, эмоционального и социального функционирования человека, основанного на его субъективной степени удовлетворенности условиями и характеристиками своей жизни, нет со- мнений в том, что ее параметры обладают независимой прогностической значимостью и являются более точными факторами состояния больного во время лечения, чем общесоматический статус [9, 4]. По мнению ряда ученых, весомый вклад в формирование КЖ человека вносит стоматологическое здоровье, поскольку оказывает существенное влияние на эстетику лица, качество питания 
человека, формирование речи, а также полноценность психики и поведение в обществе [3, 10]. С другой стороны, применение подхода и критериев, позволяющих достичь оптимального контроля над болезнью и улучшить качество жизни пациентов на основе изучения индивидуального восприятия пациентом своей болезни, выступает одним из перспективных направлений повышения эффективности диагностического и лечебного процесса при воспалительных заболеваниях полости рта [11].

Среди различных стоматологических заболеваний, определяющих социальное функционирование пациента, выраженность психических расстройств и физического дискомфорта, ведущее место занимает патология пародонта, которая в шесть раз чаще приводит к функциональным расстройствам зубочелюстной системы, обусловленных потерей зубов [12]. В структуре всех воспалительных заболеваний пародонта центральное место занимает хронический генерализованный пародонтит (ХГП), распространенность которого среди взрослого населения составляет от 65\% до 98\% и имеет тенденцию к неуклонному росту [6, 15]. Сложность этиологии и патогенеза заболевания, зависимость его от многих факторов, отсутствие первичной профилактики и нередкая рефрактерность к традиционным методам лечения, обусловливая высокую распространенность пародонтита, снижают эффективность лечебнооздоровительных мероприятий [1]. Указанные обстоятельства существенно актуализируют поиск и разработку новых перспективных методов лечения ХГП, выдвигая их на рубеж приоритетных научно-практических задач современной медицины $[5,17]$.

В исследованиях последних лет, выполненных в рамках данной проблемы, отмечается целесообразность внедрения патогенетически ориентированных методов лечения больных ХГП на основе преимущественного использования немедикаментозных лечебных факторов $[1,7]$. Именно природные и преформированные физические факторы, обладая выраженным саногенетическим потенциалом, позволяют снизить медикаментозную нагрузку при обострении заболевания, ускорить процессы выздоровления, максимально полно восстановить нарушенные функции и улучшить качество жизни человека. В связи с этим представляет интерес изучение эффективности применения озона в сочетании с транскраниальной магнитотерапией (ТМТ) в лечении заболеваний пародонта. Для озонотерапии характерны простота применения и хорошая переносимость. При этом озон обладает противогипоксическим, иммунокорригирующим действием, способен потенцировать действие антибиотиков и улучшить реологические свойства крови $[13,16]$. В то же время метод ТМТ оказывает выраженное противоотечное, анальгезирующее, противовоспалительное и спазмолитическое действие, улучшает микроциркуляцию в тканях, оптимизирует метаболические процессы [8].

Целью настоящего исследования явилась оценка качества жизни пациентов с хронически генерализованным пародонтитом при комплексном применении озона и транскраниальной магнитотерапии.

\section{МАТЕРИАЛ И МЕТОДЫ ИССЛЕДОВАНИЯ}

В исследовании приняли участие 63 пациента с ХГП легкой и средней степени тяжести в возрасте 35-50 лет (средний возраст составил $42,5 \pm 0,32$ года). Критериями включения пациентов в исследование являлись: возраст от 35 до 50 лет; верифицированный по критериям МКБ-10 диагноз «Хронический генерализованный пародонтит» 1-2 степени тяжести в стадии неполной ремиссии; длительность заболевания - от двух до десяти лет; информированное добровольное согласие на участие в исследовании. Критериями исключения выступали: общие противопоказания для проведения озонотерапии и ТМТ; хронический генерализованный пародонтит тяжелой степени; зубочелюстные аномалии и деформации; соматические заболевания в стадии декомпенсации.

В соответствии с процедурой рандомизации все обследуемые были разделены на 2 группы случайным образом, что исключает влияние субъективности исследователей, а также систематической ошибки. Первая группа (контрольная, 31 пациент) получала традиционное лечение, включающее стандартную пародонтологическую терапию (гигиеническая обработка полости рта, удаление назубных отложений, пришлифовывание зубов, аппликации на десны антимикробных (0,06\% раствор хлоргексидина, метронидазол) и противовоспалительных препаратов (индометацин, АСК), кюретаж пародонтального кармана). Пациентам второй группы (основная, 32 пациента) наряду с традиционным лечением проводили озонотерапию в сочетании с транскраниальным воздействием переменным магнитным полем низкой интенсивности.

Для озонотерапии использовали озонаторную терапевтическую установку УОТА-60-01 «Медозон» (Россия). В течение 5 мин физиологический раствор насыщали озоно-кислородной смесью, концентрация озона в котором составляла 112-123 мг/л. В растворе концентрация озона колебалась в пределах 8,6-9,5 мг/л. Озонированный 
раствор объемом 250 мл использовали для орошения пародонтальных карманов с помощью стоматологического ирригатора «Oral-В» фирмы Braun (Германия) в режиме работы «моноструя». Мощность подаваемой струи выбирали из положений от 1 до 5 на ручке регулятора давления. Озонотерапию проводили один раз в сутки, в течение 10-15 минут. Полный курс лечения включал 10 процедур, проводимых через день.

Транскраниальную магнитотерапию переменным магнитным полем осуществляли с помощью приставки «Оголовье» к аппарату «Амо-Атос», состоящей из двух полуцилиндрических излучателей переменного магнитного поля, расположенных битемпорально. Терапию проводили в положении сидя, начиная с частоты 1 Гц при продолжительности процедуры 7 мин и напряженности поля 10-30 мТл. Затем постепенно увеличивали частоту и продолжительность процедуры до 10 Гц и 12 мин соответственно, с целью адаптации к данному физическому фактору и исключения индивидуальной непереносимости. Указанная величина магнитной индукции (10-30 мТл) позволяет обеспечить достаточную глубину проникновения магнитного поля при воздействии на диэнцефальные структуры мозга. Курс магнитотерапии включал 10 процедур, проводимых через день, при этом дни проведения озонотерапии чередовались с днями магнитотерапии.

Для сравнения с референсными значениями была выбрана отдельная группа из 20 соматически и стоматологически здоровых людей, которые оставались интактными на протяжении всего исследования.

Качество жизни пациентов оценивали с помощью валидизированного в России опросника OHIP-14 - Oral Health Impact Profile [2]. Опросник ОНІР-14 представляет собой анкету из 14 вопросов, позволяющих оценивать влияние состояния полости рта на качество жизни по следующим критериям: повседневная жизнь, пережевывание пищи, способность общаться. Ответы на вопросы оцениваются по четырехбалльной шкале: 0 - никогда, 1 - редко, 2 - иногда, 3 - часто, 4 - постоянно. Чем больше сумма ответов (от 0 до 56), тем более вероятно, что человек подвержен воздействию стоматологических болезней. По итоговой сумме баллов определяют уровень качества жизни пациентов по интервалам, где 0-12 - хороший уровень качества жизни, 13-24 - удовлетворительный, 25-56 - неудовлетворительный уровень качества жизни [14].

Клиническое обследование проводилось дважды: до начала лечения и сразу после и включало выявление жалоб пациентов и оценку состояния тканей пародонта, которую проводили, используя упрощенный гигиенический индекс - OHI-S; ин- декс кровоточивости десневой борозды - SBI; папилло-маргинально-альвеолярный индекс (PMA) в модификации C. Parma (1960); пародонтальный индекс ПИ.

Статистическую обработку полученных результатов проводили с помощью пакета прикладных программ «Statistica-10», используя t-критерий Стьюдента. Различия считали достоверными при $p<0,05$. Для оценки взаимосвязи между различными показателями использовали коэффициент линейной корреляции Пирсона, уровень статистической значимости которого начинался с $\mathrm{p}<0,05$.

\section{РЕЗУЛЬТАТЫ ИССЛЕДОВАНИЯ И ИХ ОБСУЖДЕНИЕ}

Анализ результатов исследования позволил установить, что в исходном состоянии пациенты с ХГП легкой степени тяжести жаловались на появление боли $(26,3 \%)$ и кровоточивость десен $(34,2 \%)$ при чистке зубов, боль при жевании твердой пищи на стороне воспалительного процесса, неприятный запах изо рта $(65,8 \%)$. У больных средней степени тяжести боль $(76,0 \%)$ и кровоточивость десен $(84,0 \%)$ отмечались не только при чистке зубов, но и при незначительных механических нагрузках; неприятный запах изо рта был зафиксирован у всех больных (100\%). Наряду с наличием налета, зубных отложений, в том числе поддесневого зубного камня, у большинства больных средней степенью тяжести были отмечены отек $(96,0 \%)$ и гиперемия $(96,0 \%)$ десны.

Глубина пародонтальных карманов в среднем составила при ХГП легкой степени 2,1 $\pm 0,04$ мм и средней $-4,50 \pm 0,06$ мм. Степень рецессии десны у пациентов разной степени тяжести была $1,7 \pm 0,09$ мм и 2,5 $\pm 0,11$ мм соответственно. Индекс кровоточивости (SBI) у всех пациентов был достаточно высоким и колебался от $1,15 \pm 0,01$ балла у пациентов легкой степени тяжести ХГП до 2,75 $\pm 0,04$ балла у больных ХГП средней степени тяжести. Степень воспаления десны по индексу РМА составляла в первой группе $46,7 \pm 0,55 \%$ и во второй $-69,8 \pm 1,25 \%$. Подвижность зубов выявлялась только у пациентов со средней степенью пародонтита: средний показатель подвижности составил $1,4 \pm 0,07$ балла. Гигиенический индекс OHI-S у пациентов с ХГП колебался в среднем от 2,3 $\pm 0,03$ балла при легкой степени до $3,1 \pm 0,06$ балла - при средней степени тяжести ХГП, что свидетельствовало о неудовлетворительной и плохой гигиене полости рта. Различия между клиническими показателями у пациентов двух групп были статистически значимыми $(\mathrm{p}<0,05)$. 
Таким образом, проведенное сравнение выявило, что исходные клинические показатели у обследованных пациентов достоверно различались $(\mathrm{p}<0,01)$ в зависимости от тяжести ХГП. При средней степени тяжести ХГП наблюдалось увеличение всех основных клинических показателей в 1,3-2,4 раза по сравнению с пациентами, у которых ХГП протекает в более легкой форме.

Оценка КЖ пациентов с ХГП, проведенная с помощью опросника ОНІР-14 (табл. 1), показала, что исходные значения основных критериев опросника, а также интегральный показатель OHIP-14 в 5,5-7,8 раза $(\mathrm{p}<0,01)$ превышали показатели у здоровых лиц, достигая неудовлетворительного уровня КЖ. Сравнение интегральных показателей OHIP-14 у пациентов с различной стадией заболевания позволило установить большее снижение КЖ у больных средней степени тяжести, выразившееся в повышении данного параметра на $31 \%(\mathrm{p}<0,05)$. Статистически значимые различия в снижении КЖ больных ХГП легкой и средней степени заболевания наблюдались по всем критериям опросника. При этом наибольшее различие было зафиксировано по критерию «Пережевывание пищи» $(+42 \% ; \mathrm{p}<0,05)$ и «Способность общаться» $(+35 \%$; $<<0,05)$.

После проведенного курса лечебных мероприятий наблюдалось существенное улучшение самочувствия больных и нормализация клинической картины. Более выраженный клинический эффект был зафиксирован в основной группе больных, где в состав комплексной терапии входили озон и ТМТ. Случаев осложнения и побочного действия в результате применения озоно- и магнитотерапии выявлено не было.

Положительная динамика клиникофункционального состояния пациентов с ХГП подтверждается результатами оценки КЖ, представленными в табл. 2. При этом, несмотря на то что в обеих наблюдаемых группах отмечались достоверные положительные изменения, более выраженное улучшение КЖ было выявлено в основной группе. В то же время необходимо отметить, что результаты после лечения даже в группе с курсовым применением озона и ТМТ продолжали оставаться достоверно ниже параметров КЖ здоровых лиц.

Исходные показатели качества жизни (OHIP-14) пациентов с ХГП с различной степенью тяжести

\begin{tabular}{|l|c|c|c|}
\hline \multicolumn{1}{|c|}{ Критерии } & \multirow{2}{*}{ Показатели } & \multicolumn{2}{|c|}{ Степень тяжести ХГП } \\
\cline { 3 - 4 } & здоровых лиц & Легкая & Средняя \\
\hline $\begin{array}{l}\text { Пережевывание пищи } \\
\text { (сумма баллов п.п. 1-5) }\end{array}$ & $1,61 \pm 0,10$ & $8,83 \pm 0,57^{*}$ & $12,58 \pm 0,82 * \#$ \\
\hline $\begin{array}{l}\text { Способность общаться } \\
\text { (сумма баллов п.п. 6-10) }\end{array}$ & $1,44 \pm 0,09$ & $8,10 \pm 0,53^{*}$ & $10,94 \pm 0,71 * \#$ \\
\hline $\begin{array}{l}\text { Повседневная жизнь } \\
\text { (сумма баллов п.п. 11-14) }\end{array}$ & $1,25 \pm 0,08$ & $7,30 \pm 0,47 *$ & $8,46 \pm 0,54 * \#$ \\
\hline $\begin{array}{l}\text { Общее качество жизни } \\
\text { (сумма баллов п.п. 1-14) }\end{array}$ & $4,30 \pm 0,28$ & $24,23 \pm 1,55^{*}$ & $31,98 \pm 2,07 * \#$ \\
\hline
\end{tabular}

Примечание: * - достоверное отличие от соответствующего показателя здоровых лиц при р <0,05; \# - достоверное отличие от соответствующего показателя больных с легкой степенью тяжести ХГП при р<0,05.

Таблица 2

Динамика показателей качества жизни (ОНІР-14) больных

ХГП при курсовом применении озона в сочетании с ТМТ

\begin{tabular}{|l|c|c|c|c|}
\hline \multirow{2}{*}{ Критерии } & \multicolumn{2}{|c|}{ Контрольная группа } & \multicolumn{2}{c|}{ Основная группа } \\
\cline { 2 - 5 } & До лечения & $\begin{array}{c}\text { После } \\
\text { лечения }\end{array}$ & До лечения & $\begin{array}{c}\text { Лосле } \\
\text { ленения }\end{array}$ \\
\hline $\begin{array}{l}\text { Пережевывание пищи } \\
\text { (сумма баллов п.п. 1-5) }\end{array}$ & $10,55 \pm 0,69$ & $9,28 \pm 0,60^{*}$ & $10,86 \pm 0,71$ & $4,45 \pm 0,28 * \#$ \\
\hline $\begin{array}{l}\text { Способность общаться } \\
\text { (сумма баллов п.п. 6-10) }\end{array}$ & $9,47 \pm 0,62$ & $8,71 \pm 0,57$ & $9,57 \pm 0,62$ & $5,26 \pm 0,31 * \#$ \\
\hline $\begin{array}{l}\text { Повседневная жизнь } \\
\text { (сумма баллов п.п. 11-14) }\end{array}$ & $7,92 \pm 0,51$ & $7,29 \pm 0,47$ & $7,84 \pm 0,51$ & $5,56 \pm 0,33 * \#$ \\
\hline $\begin{array}{l}\text { Общее качество жизни } \\
\text { (сумма баллов п.п. 1-14) }\end{array}$ & $27,94 \pm 1,82$ & $25,28 \pm 1,52$ & $28,27 \pm 1,84$ & $15,27 \pm 0,92 * \#$ \\
\hline
\end{tabular}

Примечание: * - достоверное отличие от соответствующего показателя до лечения при р <0,05; \# - достоверное отличие от соответствующего показателя контрольной группы при р <0,05. 
Результаты корреляционного анализа между доменами качества жизни (OHIP-14) и индексными показателями стоматологического статуса пациентов с ХГП

\begin{tabular}{|l|c|c|c|c|}
\hline \multicolumn{1}{|c|}{ Критерии } & OHI-S & SBI & PMA & ПИ \\
\hline $\begin{array}{l}\text { Пережевывание пищи } \\
\text { (сумма баллов п.п. 1-5) }\end{array}$ & $0,52^{*}$ & $0,59^{*}$ & $0,64^{*}$ & $0,45^{*}$ \\
\hline $\begin{array}{l}\text { Способность общаться } \\
\text { (сумма баллов п.п. 6-10) }\end{array}$ & $0,55^{*}$ & $0,40^{*}$ & $0,43^{*}$ & $0,42^{*}$ \\
\hline $\begin{array}{l}\text { Повседневная жизнь } \\
\text { (сумма баллов п.п. 11-14) }\end{array}$ & 0,34 & $0,47^{*}$ & 0,30 & 0,32 \\
\hline $\begin{array}{l}\text { Общее качество жизни } \\
\text { (сумма баллов п.п. 1-14) }\end{array}$ & $0,43^{*}$ & $0,50^{*}$ & $0,47 *$ & $0,40^{*}$ \\
\hline
\end{tabular}

Примечание: * - уровень значимости коэффициента корреляции Пирсона при р<0,05.

Под влиянием сочетанного применения физиофакторов мы наблюдали достоверное повышение КЖ по всем критериям. В контроле достоверный характер носили изменения домена, характеризующего проблемы при приеме пищи. В частности, КЖ по критерию «Пережевывание пищи» в основной группе улучшилось в 2,4 раза $(\mathrm{p}<0,05)$, в то время как в контрольной группе данный домен изменился лишь на $12 \%(\mathrm{p}<0,05)$. На наш взгляд, отсутствие болевых ощущений в полости рта при жевании пищи, особенно на стороне воспалительного процесса, а также уменьшение величины пародонтальных карманов и показателя подвижности зубов существенно улучшили качество питания пациентов. Суммарный показатель «Способность общаться» в основной группе по сравнению с исходными данными улучшился на $45 \%(\mathrm{p}<0,05)$, в контрольной группе этот параметр изменился лишь на $8 \%$, проявляя характер тенденции $(\mathrm{p}<0,1)$. При этом пациенты отмечали, что снижение выраженности халитоза, существенно облегчило общение с людьми, предоставив возможность чувствовать себя более свободно. Суммарный балл по вопросам 11-14, характеризующим проблемы в повседневной жизни (работа, отдых), в группе с озоно- и магнитотерапией снизился на $29 \%(\mathrm{p}<0,05)$, демонстрируя рост КЖ по данному критерию, что обеспечило пациентам основной группы возможность более активного участия в общественной жизни. Суммарная критериальная оценка КЖ в основной группе характеризовалась его достоверным улучшением на $46 \%(\mathrm{p}<0,05)$, что в 2,8 раза превосходит изменения данного параметра в контрольной группе.

Для оценки степени зависимости показателей КЖ ОНІР-14 от клинических показателей ХГП был проведен корреляционный анализ, результаты которого представлены в табл. 3. Матрица переменных была составлена из данных после курса проведенного лечения.
Результаты проведенного корреляционного анализа между КЖ и клиническими параметрами, характеризующими тяжесть ХГП, выявили положительные коэффициенты корреляции, преимущественно средней силы. Наиболее существенная корреляционная связь установлена между стоматологическими индексами и критерием опросника OHIP-14 «Пережевывание пищи» ( $\mathrm{r}=0,45-0,64$; $\mathrm{p}<0,05)$. Вопросы, составляющие данную шкалу, позволяют пациенту интерпретировать собственные ощущения боли, дискомфорта и затруднения при приеме пищи.

Детальный анализ корреляционной взаимосвязи значений гигиенического индекса OHI-S co шкалами КЖ выявил наибольшую силу связи с такими критериями, как «Повседневная жизнь» $(\mathrm{r}=0,55 ; \mathrm{p}<0,05)$ и «Пережевывание пищи» $(\mathrm{r}=0,52 ; \mathrm{p}<0,05)$. Наличие зубного налета и камня часто сопровождается неприятным запахом изо рта, затрудняя общение между людьми в коллективе, что сказывается на профессиональной деятельности, ставит в неловкое положение. Кроме этого, плохая гигиена полости рта, как правило, является причиной развития воспаления в десне, что объясняет наличие выраженного болевого симптома и затруднений при приеме пищи у пациентов с ХГП при ухудшении показателей гигиенического индекса.

Анализ корреляционной зависимости шкал опросника ОНІР-14 со степенью кровоточивости десны (индекс SBI) установил максимальную связь со шкалой «Пережевывание пищи» $(\mathrm{r}=0,59$; $\mathrm{p}<0,05)$. Также достаточно существенной была связь индекса SBI со шкалой «Повседневная жизнь» $(\mathrm{r}=0,47 ; \mathrm{p}<0,05)$. Между значениями индекса РМА и шкалой «Пережевывание пищи» также наблюдается максимальное значение корреляции $(\mathrm{r}=0,64 ; \mathrm{p}<0,05)$. Степень воспаления десны и выраженность кровоточивости напрямую связаны с выраженностью болевого симптома во время приема пищи, что приводит к нарушению полноценного питания. 
Изучение корреляционных связей между ответами респондентов по шкалам ОНIP-14 и значениями ПИ выявило умеренную взаимосвязь данного клинического показателя с КЖ пациентов. Так, максимальная корреляционная связь установлена по шкалам «Пережевывание пищи» и «Способность общаться» ( $\mathrm{r}=0,45$ и $\mathrm{r}=0,42$ соответственно; $\mathbf{p}<0,05)$. Значение ПИ характеризует степень тяжести ХГП. С его увеличением усиливается выраженность болевого симптома и дискомфорта во время приема пищи, страдают функции речеобразования, артикуляции, фонации, вкусоощущения, что затрудняет полноценное общение в коллективе, сказывается на эффективности работы и отдыха.

Таким образом, выявленная совокупность зависимостей клинических показателей с разными шкалами ОНІР-14 отличается неоднородностью и зависит от того, на какой критерий КЖ в большей степени влияет тот или иной клинический показатель. Тот факт, что обнаруженная корреляционная связь по всем клиническим показателям не является сильной, позволяет полагать, что на КЖ оказывают влияния не только клинические значения, но и другие факторы (например, субъективное мнение пациентов). Анализ выявил, что критерии корреляции между клиническими показателями (OHI-S, SBI, PMA, ПИ) и шкалой «Пережевывание пищи» максимальные и в среднем составляют 0,55. На наш взгляд, вопросы, составляющие домен «Пережевывание пищи», могут быть использованы в качестве индикатора эффективности проведенного стоматологического лечения.

В целом полученные результаты свидетельствуют о том, исходное состояние больных ХГП характеризовалось выраженным снижением КЖ и его критериев по сравнению с показателями здоровых лиц. Курсовое применение озона в сочетании с ТМТ у больных ХГП по сравнению с традиционным лечением является более эффективным терапевтическим методом, обеспечивающим достоверную положительную динамику субъективных признаков и основных стоматологических индексов. Наблюдаемый регресс клинических проявлений заболевания лежит в основе выраженного улучшения качества жизни пациентов, что позволяет им вести полноценную жизнь, не испытывая неудобства, связанного с приемом пищи и общением с людьми. Совокупность выявленных положительных зависимостей между показателями стоматологического статуса и доменами КЖ доказывает информативность использования опросника ОНІР-14 в качестве критерия выбора метода терапии и оценки клинической эффективности проводимого лечения ХГП.

\section{КОНФЛИКТ ИНТЕРЕСОВ}

Авторы декларируют отсутствие явных и потенциальных конфликтов интересов, связанных с публикацией настоящей статьи.

\section{ЛИТЕРАТУРА / REFERENCES}

1. Аверьянов С.В., Галиуллина Э.Ф., Шакиров Д.Ф. Современные аспекты лечебно-профилактической терапии воспалительного заболевания пародонта // Успехи современной науки и образования. 2017. - T. 4, № 3. - C. 71-76. [Averyanov S.V., Galiullina E.F., Shakirov D.F. Modern aspects of therapeutic and prophylactic treatment of inflammatory periodontal diseases. Uspekhi sovremennoy nauki i obrazovaniya. 2017; 4(3): 71-76 (in Russ.)].

2. Барер Г.М., Гуревич К.Г., Смирнягина В.В., Фабрикант Е.Г. Валидация русскоязычной версии опросника OHIP у пациентов с диагнозом хронический генерализованный пародонтит средней степени тяжести // Стоматология. - 2007. - Т. 58, № 5. - C. 27-30. [Barer G.M., Gurevich K.G., Smirnyagina V.V., Fabrikant E.G. Validation of Oral Health Impact Profile (OHIP) quality oflife questionnaire in Russian patients with evidence of chronic generalized periodontitis. Stomatologiya. 2007; 58(5): 27-30 (in Russ.)].

3. Беленова И.А., Кобзева Г.Б. Влияние воспалительных заболеваний пародонта на качество жизни индивидуума, возможности реабилитации // Вестник новых медицинских технологий. Электронное издание. - 2014. - № 1. - C. 56-59. - DOI: 10.12737/4794. [Belenova I.A., Kobzeva G.B. Effect of the inflammatory periodontal disease on quality of life of the individual and recovery possibilities. Vestnik novykh meditsinskikh tekhnologiy. Elektronnoye izdaniye.2014; (1): $56-59$ (in Russ.)].

4. Булкина Н.В., Турусова Е.В., Перунов А.Ю. Качество жизни как критерий выбора метода лечения включенных дефектов зубных рядов у пациентов с генерализованным пародонтитом // Фундаментальные исследования. - 2012. - № 7-1. - С. 50-53. [Bulkina N.V., Turusova E.V., Perunov A.J. Quality of life as a criterion for the choice of the method of treatment included dentition defects in patients with generalized periodontitis. Fundamental'nyye issledovaniya. 2012; (7-1): 50-53 (in Russ.)].

5. Жданов М.С., Мамедханов А.3. Пародонтит // Студенческий вестник. - 2018. - № 13-2 (33). C. 34-38. [Zhdanov M.S., Mamedkhanov A.Z. Periodontitis. Studencheskiy vestnik. 2018; (13-2 (33)): 34-38 (in Russ.)].

6. Максимовский Ю.М., Гуревич К.Г., Фабрикант Е.Г., Федоткина О.В. Качество жизни и поведенческие факторы риска пациентов с патологией полости рта и челюстно-лицевой области // Стоматология для всех. - 2013. - № 4. - С. 34-36. [Maksimovskiy Yu.M., Gurevich K.G., Fabrikant E.G., Fedotkina O.V. Quality of life and behavioural risk factors of patients with pathology of an oral cavity and maxillofacial area. Stomatologiya dlya vsekh. 2013; (4): 34-36 (in Russ.)]. 
7. Нагорнев С.Н., Рамазанов Н.Г., Гусакова Е.В., Пузырева Г.А. Динамика клинико-функционального состояния пациентов с дентальными периимплантитами в условиях комплексного применения импульсного магнитного поля и озонотерапии // Системный анализ и управление в биомедицинских системах. - 2015. - Т. 14, № 3. - С. 408-416. [Nagornev S.N., Ramazanov N.G., Gusakova E.V., Puzyreva G.A. The dynamics of clinical and functional status of patients with dental pery-implantitis in terms of the integrated application of pulsed magnetic field and ozonoterapie. Sistemnyy analiz i upravleniye v biomeditsinskikh sistemakh. 2015; 14(3): 408-416 (in Russ.)].

8. Нагорнев С.Н., Фролков В.К., Кулиш А.В., Самсонова О.С. Методология системного применения транскраниальных магнитных воздействий в условиях гемоциркуляторных и дисметаболических нарушений // Russian Journal of Rehabilitation Medicine. - 2016. - № 2. - C.32-44. [Nagornev S.N., Frolkov V.K., Kulish A.V., Samsonova O.S. Methodology of system use of transscranial magnetic exposures under conditions of hemocyricular and dismitabolic disturbances. Russian Journal of Rehabilitation Medicine. 2016; (2): 32-44 (in Russ.)].

9. Новик А.А., Ионова Т.И. Руководство по исследованию качества жизни в медицине. - 2-е изд. - М. : ЗАО «ОЛМА Медиа Групп», 2007. - 320 с. [Novik A.A., Ionova T.I. Guide to the study of the quality of life in medicine. $2^{\text {nd }}$ ed. M. : ZAO «OLMA Media Grupp»; 2007: 320 (in Russ.)].

10. Пародонтология. Национальное руководство / Под ред. проф. Л.А. Дмитриевой. - М. : ГЭОТАРМедиа, 2013. - 712 c. [Periodontics. National manual. Prof. L.A. Dmitriyeva, editor. M. : GEOTARMedia; 2013: 712 (in Russ.)].

11. Пешков М.В., Гуревич К.Г., Вагнер В.Д. Качество жизни пациентов, обращающихся за стоматологической хирургической помощью // Системный анализ и управление в биомедицинских системaх. - 2013. - Т. 12, № 4. - С. 888-895. [Peshkov M.V., Gurevich K.G., Vagner V.D. Quality of life of the patiens, undergoing dental surgical treatment. Sistemnyy analiz i upravleniye $\mathrm{v}$ biomeditsinskikh sistemakh. 2013; 12(4): 888-895 (in Russ.)].

12. Пешков М.В., Гуревич К.Г. Социальная характеристика и качество жизни пациентов, обращающихся за стоматологической хирургической помощью //
Российский медико-биологический вестник им. академика И.П. Павлова. - 2016. - Т. 24, № 1. C. 123-128. [Peshkov M.V., Gurevich K.G. Social characteristics and quality of life of patients seeking surgical care dental. Rossiyskiy medikobiologicheskiy vestnik im. akademika I.P. Pavlova. 2016; 24(1): 123-128 (in Russ.)].

13. Сотиева 3.К., Хетагуров С.К. Изучение эффективности озонотерапии при воспалительных заболеваниях пародонта // Журнал научных статей Здоровье и образование в XXI веке. - 2016. - Т. 18, № 1. - C.77-80. [Sotieva Z.K., Khetagurov S.K. The efficiency of ozone treatment of inflammatory periodontal diseases. Zhurnal nauchnykh statey Zdorov'ye i obrazovaniye v XXI veke. 2016; 18(1): 77-80 (in Russ.)].

14. Студеникин P.B., Серикова О.В. Оценка качества жизни пациентов в стоматологии с помощью компьютерной программы // Журнал научных статей Здоровье и образование в XXI веке. - 2017. - Т. 19, № 12. - C. 234-239. [Studenikin R.V., Serikova O.V. Assessment of the quality of life of patients in dentistry using computer programs. Zhurnal nauchnykh statey Zdorov'ye i obrazovaniye v XXI veke. 2017; 19(12): 234-239 (in Russ.)].

15. Федоткина О.В., Шиикина И.М., Дмитриева Е.А., Фабрикант Е.Г., Гуревич К.Г. Влияние кариеса на качество жизни пациентов // Эндодонтия today. 2014. - № 1. - C. 25-29. [Fedotkina O.V., ShishkinaI.M., Dmitrieva E.A., Fabrikant E.G., Gurevich K.G. The impact of the dental caries on the quality of patients' life. Endodontiya today. 2014; (1): 25-29 (in Russ.)].

16. Филиппова Л.А., Герасименко О.В. Применение озонотерапии в комплексном лечении генерализованного пародонтита // Главный врач Юга России. - 2017. - Т. 55. - С. 13-15. [Filippova L.A., Gerasimenko O.V. The application of ozonotherapy in the complex treatment of generalized periodontitis. Glavnyy vrach Yuga Rossii. 2017; 55: 13-15 (in Russ.)].

17. Щербакова T.A. Обзор современных методов лечения генерализованного агрессивного пародонтита // Бюллетень медицинских интернет-конференций. - 2017. - Т. 6, № 1. - С. 415-419. [Shcherbakova T.A. Modern methods of treatment of generalized aggressive periodontitis. Byulleten' meditsinskikh internet-konferentsiy. 2017; 6(1): 415-419 (in Russ.)].

Поступила в редакцию 09.10.2018 Подписана в печать 20.12.2018 